\title{
The influence of sardine consumption on the omega-3 fatty acid content of mature human milk
}

\author{
Influência da ingestão de sardinha nos níveis de ácidos graxos poliinsaturados \\ da série $\omega 3$ no leite materno
}

\author{
Rose V. Patin ${ }^{1}$, Márcia R. Vítolo², Mara A. Valverde¹, Patrícia 0. Carvalho3, \\ Gláucia M. Pastore ${ }^{3}$, Fábio Ancona Lopez ${ }^{4}$
}

\section{Resumo}

Objetivos: A proposta deste trabalho foi verificar a influência da ingestão de sardinha, alimento rico em ácidos graxos poliinsaturados da série $\omega 3$, na composição do leite materno.

Métodos: Estudo prospectivo avaliou 31 nutrizes acompanhadas no Hospital Guilherme Álvaro, as quais receberam $2 \mathrm{~kg}$ de sardinha fresca por duas vezes, em intervalos de 15 dias. Nos tempos 0,15 e 30 dias, realizou-se inquérito alimentar de 24 horas e coleta de leite. Determinaram-se os ácidos graxos do leite materno por cromatografia a gás. Para análise estatística dos resultados, utilizaram-se testes não paramétricos, com nível de significância $p<0,05$.

Resultados: Os resultados mostraram que o consumo alimentar das nutrizes estava adequado e apresentou-se constante durante os três momentos do estudo. Quanto aos ácidos graxos da série $\omega 3$ no leite, verificou-se que o consumo regular e os menores intervalos entre coleta de leite e ingestão de sardinha determinaram maiores proporções de ácido docosapentaenóico e ácido docosahexaenóico após 15 e 30 dias do início do estudo. Os ácidos graxos da série $\omega 6$ e $\omega 3$ apresentaram correlação significante, $r^{2}=0,58$ e 0,59 , respectivamente, nos tempos 15 e 30 dias.

Conclusão: Esses resultados sugerem que a ingestão de peixe incorporada ao hábito alimentar da nutriz durante a lactação, com o consumo de $100 \mathrm{~g}$ de sardinha, duas a três vezes por semana, contribui para o aumento dos ácidos graxos da série $\omega 3$.

J Pediatr (Rio J). 2006;82(1):63-9: Leite materno, ácidos graxos poliinsaturados, ingestão de peixe, ácido docosahexaenóico (DHA), ácidos graxos $\omega 3$, lactação.

\section{Abstract}

Objectives: The purpose of this study was to investigate what effect the ingestion of sardines, rich in omega- 3 series polyunsaturated fatty acids, has on the composition of breastmilk.

Methods: This was a prospective study of 31 nursing mothers under observation at the Hospital Guilherme Álvaro. Each was given $2 \mathrm{~kg}$ of fresh sardines twice with a 15-day interval. Milk was sampled and a 24-hour dietary recall questionnaire was applied on days 0,15 and 30 . Milk was assayed for fatty acid content by gas chromatography. Statistical analysis of the results was performed using nonparametric tests with significance set at $p<0.05$.

Results: The results demonstrate that the nutritional intake of the nursing mothers was adequate at all three sample points. With regard to the omega- 3 series fatty acid content of the breastmilk, it was observed that regular consumption and shorter intervals between ingestion and milk collection resulted in higher concentrations of docosapentaenoic acid and docosahexaenoic acid at 15 and 30 days into the study. Fatty acids from the omega- 3 and omega- 6 series exhibited a significant correlation, $\mathrm{r}^{2}$ was 0.58 and 0.59 at 15 and 30 days, respectively.

Conclusion: These results suggest that incorporating fish into the diets of nursing mother during lactation, in the form of $100 \mathrm{~g}$ of sardines two or three times a week, contributes to an increase in omega-3 series fatty acids.

J Pediatr (Rio J). 2006;82(1):63-9: Breastmilk, human milk, polyunsaturated fatty acids, fish intake, fish consumption, docosahexaenoic acid (DHA), omega-3 fatty acids, lactation, breastfeeding.

\section{Introdução}

A maturação do sistema nervoso central tem início na fase intra-uterina e persiste até os 7 anos, apresentando maior intensidade nos primeiros 2 anos de vida ${ }^{1}$. O processo morfogênico, diretamente associado à função do cérebro, requer uma oferta de ácidos graxos (AG) específica, especialmente de ácidos araquidônico e docosahexaenóico (DHA). Esse processo torna a nutrição materna essencial ao feto durante a gestação e lactação, pois há aumento funcional e bioquímico das demandas maternas de ácidos graxos poliinsaturados (AGP) de cadeia longa 2-4. 
Os AG de cadeia longa da série ômega $3(\omega 3)$ são encontrados no cérebro e na retina e participam do crescimento contribuindo para o processo de mielinização e desenvolvimento da função da visão, no desenvolvimento psicomotor e em vários aspectos da função neural em relação ao comportamento ${ }^{1-5}$.

Com o nascimento, esses AG essenciais são transferidos aos lactentes em quantidades suficientes pelo leite materno de mães com adequado estado nutricional. Em países em desenvolvimento, onde as condições de saúde e nutrição são precárias, possíveis deficiências podem acarretar prejuízos nos processos de elongação e dessaturação, ou seja, no processo de formação de ácidos araquidônico e docosahexaenóico a partir dos ácidos linoléico e linolênico, respectivamente ${ }^{1,2,4}$.

Estudos comparando crianças em aleitamento materno e em uso de fórmulas lácteas demonstraram maiores proporções de AGP de cadeia longa, bem como aumento da acuidade visual no primeiro grupo ${ }^{6}$. Em pré-termos (com menos de 32 semanas de gestação), quando comparados a crianças a termo, observou-se, no primeiro grupo, menores concentrações de DHA no cérebro, fígado e células sangüíneas, como também menor acuidade visual ${ }^{1,6}$.

Populações com hábito de consumir peixes marinhos têm maiores proporções de AG $\omega 3$ no leite, quando comparadas a outras que raramente ingerem esse produto ${ }^{7-9}$. Estudos em que nutrizes foram suplementadas com óleo de peixe encontraram níveis satisfatórios de AG da série $\omega 3$ no leite produzido $8,10,11$.

Evidências demonstram a influência da dieta na composição do leite materno. Assim, a proposta do presente trabalho foi verificar se o consumo de sardinha, como fonte de AG da série $\omega 3$, em quantidades facilmente incorporáveis aos hábitos alimentares, modula os níveis desses nutrientes no leite maduro secretado. Essa orientação poderia ser utilizada na população geral e, principalmente, nos grupos vulneráveis, como crianças prematuras e de baixo peso ao nascer.

\section{Métodos}

Foram acompanhadas 31 nutrizes (amostra de conveniência) do Ambulatório de Puericultura do Centro de Lactação no Hospital Guilherme Álvaro, Santos (SP). Todas foram entrevistadas e, após sua inclusão no estudo, realizou-se coleta de leite, recordatório alimentar de 24 horas (início, 15 e 30 dias) e fornecimento de sardinha no período inicial e aos 15 dias.

Para fazer parte do trabalho, as mães tinham que preencher os seguintes critérios: estar praticando aleitamento materno exclusivo (sem oferta de água, chá ou leite de vaca e uso de mamadeiras); não ser fumante; não apresentar doenças no período pré- ou pós-parto; não estar fazendo uso de medicamentos; não apresentar alergia ou intolerância à sardinha no período pré ou pós-gestacional; ter disponibilidade de comparecer aos retornos. Com relação aos lactentes e à gestação, estes deveriam apresentar peso de nascimento igual ou superior a $2.500 \mathrm{~g}$; idade gestacional entre 37 e 42 semanas; não apresentarem doenças ou intercorrências no período perinatal ou pósnatal e terem idade igual ou maior do que 15 dias de vida, no início do estudo.

O termo de consentimento, aprovado pelo comitê de ética da Universidade Federal de São Paulo (UNIFESP-EPM), foi obtido de cada mãe no início do estudo.

Avaliou-se o número de gestações, número de partos, ganho de peso gestacional, medidas antropométricas (peso e estatura) das nutrizes, e o índice de massa corporal (IMC) verificou o estado nutricional segundo critérios da OMS ${ }^{12}$, que considera eutrofia valores entre 18,5 e $24,9 \mathrm{~kg} / \mathrm{m}^{2}$, préobesidade (sobrepeso) de 25 a $29,9 \mathrm{~kg} / \mathrm{m}^{2}$ e obesidade grau I de 30 a $34,9 \mathrm{~kg} / \mathrm{m}^{2}$, obesidade grau II de 35 a $39,9 \mathrm{~kg} / \mathrm{m}^{2}$, obesidade grau III $\geq 40 \mathrm{~kg} / \mathrm{m}^{2}$.

$O$ inquérito alimentar utilizado em cada momento do estudo (T0, T15 e T30) foi o recordatório alimentar de 24 horas $^{13}$. Para quantificar a ingestão das nutrizes em relação às calorias, macronutrientes (proteínas, carboidratos e lipídeos), AG saturados, poliinsaturados e monoinsaturados e colesterol da dieta, utilizou-se o Programa de Apoio à Nutrição versão 2.5 do Centro de Informática à Saúde da Universidade Federal de São Paulo/Escola Paulista de Medicina ${ }^{14}$.

Cada nutriz recebeu $4 \mathrm{~kg}$ de sardinha fresca $(2 \mathrm{~kg}$ no tempo 0 e $2 \mathrm{~kg}$ no tempo 15 dias), sendo orientada a ingerilas no mínimo duas vezes por semana, a fim de atingir a quantidade de $500 \mathrm{~g}$ por semana. Com relação ao preparo, respeitou-se o hábito da própria população, que demonstrou preferir o consumo da sardinha frita, garantindo a oferta regular de AGP de cadeia longa. A quantidade oferecida à mãe foi estimada prevendo a diluição intrafamiliar. Após o consentimento das nutrizes em fazer parte do estudo, realizou-se a coleta de leite em três momentos: tempo inicial (T0), aos 15 dias (T15) e aos 30 dias (T30).

No momento da coleta de leite dos tempos T15 e T30, a mãe foi questionada quanto à forma e freqüência com que consumiu a sardinha durante as 2 semanas anteriores.

As amostras de leite maduro foram coletadas por expressão manual, como descrito por Marmet ${ }^{15}$. Antes da coleta, realizou-se higienização das mamas com gazes esterilizadas e umedecidas em água desionizada. Padronizou-se a coleta com a retirada do leite (mínimo de $40 \mathrm{ml}$ ) logo após a mamada, e em ambas as mamas. Para a coleta, utilizaram-se frascos de polipropileno, os quais foram tratados previamente. Após a coleta, as amostras foram devidamente transportadas e congeladas a $-20{ }^{\circ} \mathrm{C}$.

Após o descongelamento do leite, separou-se uma porção de $5 \mathrm{ml}$, a fim de realizar a extração dos lipídeos pelo método de Folch et al. ${ }^{16}$. A quantidade de gordura total foi obtida pelo método gravimétrico. Os ésteres metílicos de AG das frações lipídicas foram determinados pelo método de Hartman \& Lago $^{9}$ e identificados por cromatografia gasosa17. O cromatógrafo a gás utilizado foi o Chrompack CP $9001^{\circledR}$ com detector de ionização de chama (FID) com coluna capilar de sílica fundida CPsil 88 de 50 por $0,25 \mathrm{~mm}$ e temperatura do detector e do injetor 270 e $250{ }^{\circ} \mathrm{C}$, 
respectivamente. Utilizou-se fluxo de gases para o detector de ionização de chama $\mathrm{H}_{2}$ de $40 \mathrm{ml} /$ minuto, com $\mathrm{N}_{2}$ de $40 \mathrm{ml} /$ minuto e o ar sintético de $40 \mathrm{ml} /$ minuto. A programação de temperatura realizada foi: $180{ }^{\circ} \mathrm{C}$ durante 12 minutos, seguido de aquecimento de $5{ }^{\circ} \mathrm{C}$ por minuto até $220^{\circ} \mathrm{C}$, sendo a temperatura mantida nos últimos 5 minutos, finalizando o tempo de corrida em 25 minutos.

Os AG do leite materno foram identificados utilizando como standard padrões de AG da SIGMA ${ }^{\circledR}$ por comparação direta do tempo de retenção de seus $A G$ metil ésteres e quantificados na forma percentual do total de AG. Esses procedimentos também foram realizados para determinar a composição da sardinha.

Para análise dos resultados, foram aplicados os seguintes testes não paramétricos: análise de variância por postos de Friedman ${ }^{18}$, a fim de comparar a dieta e a composição de AG do leite materno nos tempos estudados. Essa mesma análise foi aplicada para a gordura total do leite materno; teste de comparações múltiplas ${ }^{18}$ - foi aplicado quando a análise de variância mostrou valores significantes; teste de Wilcoxon ${ }^{18}$ - para comparar os valores do delta $\%(\Delta \%)$ em cada ácido graxo estudado e para gordura total; coeficiente de correlação de Spearman ${ }^{18}$ - para estudar a relação entre $\omega 6$ e $\omega 3$ nos diferentes tempos do estudo; teste de MannWhitney 18 - para estudar as medidas efetuadas do $\Delta \%$ entre dias de consumo próximos/regulares e distantes/ irregulares. Fixou-se em 0,05 ou $5 \%(\alpha \leq 0,05)$ o nível de rejeição da hipótese de nulidade, assinalando com um asterisco os valores significantes.

\section{Resultados}

As nutrizes estudadas apresentaram idade média de 27,9 anos $( \pm 6,3)$, peso no momento inicial do estudo de $61,2 \mathrm{~kg}( \pm 10,8)$, estatura de $158,2 \mathrm{~cm}( \pm 5,3)$ e IMC médio de $24,3 \mathrm{~kg} / \mathrm{m}^{2}( \pm 4,2)$. A distribuição quanto à paridade das mães mostrou predominância de multíparas (61,3\%). 0 ganho de peso gestacional médio foi de $10,9 \mathrm{~kg}( \pm 6,5)$. A classificação do estado nutricional ${ }^{12}$ revelou maior freqüência de mães eutróficas $(58,1 \%)$ e sobrepeso $(32,3 \%)$. Quanto aos lactentes, apresentaram peso de nascimento médio de $3.286 \mathrm{~g}( \pm 456)$, estatura de nascimento de $49,5 \mathrm{~cm}( \pm 2,2)$ e idade média de 22,7 dias de vida no primeiro momento do estudo (TO).

Foram analisados 30 inquéritos alimentares nos tempos T0, T15 e T30, com exclusão de uma mãe por não estar em condições adequadas de respondê-lo.

Com relação ao padrão alimentar prévio das nutrizes, observou-se que apenas cinco tinham o hábito de consumir peixe mais do que uma vez por semana, ou seja, $83,3 \%$ das nutrizes $(n=26)$ tinham consumo semanal de peixe menor do que a proposta do presente trabalho.

A análise da dieta das mães não demonstrou variação nos três períodos de coleta de dados (Tabela 1 ).

A composição de AG da sardinha frita foi analisada em $\%$ do total dos ácidos (Tabela 2). No leite materno, analisou-se a composição em \% do total dos AG, nos momentos T0, T15 e T30. Para cada análise, utilizou-se a análise de variância por postos de Friedman e o teste de Wilcoxon, utilizando o $\Delta \%, \Delta 1$ (T15 - T0/T0 x 100) e $\Delta 2$ (T30 - T0/ T0 $\times$ 100) (Tabela 3). Para essas análises, não se verificaram diferenças estatísticas.

No leite materno, correlacionou-se a quantidade encontrada de AGP da série $\omega 6$ e $\omega 3$ para os tempos T0, T15 e T30, sendo utilizado para essa análise o coeficiente de correlação de Spearman. A correlação foi estatisticamente significante para os tempos T15 $\left(r^{2}=0,58\right)$ e T30 $\left(r^{2}=0,59\right)(p<0,05)$ (Tabela 3).

Devido às diferenças encontradas na distribuição de ingestão da sardinha nas semanas de estudo, decidiu-se classificar as nutrizes em grupos quanto à freqüência e intervalo entre o consumo da sardinha e o dia da coleta de leite, com o objetivo de verificar possíveis diferenças nas concentrações de AG entre os grupos, determinada por esse fato. Essa análise foi realizada separadamente para o

Tabela 1 - Ingestão alimentar das nutrizes - valor energético total (VET), proteínas, carboidratos, lipídeos, g e \% em relação ao VET, ácidos graxos saturados, monoinsaturados e poliinsaturados nos tempos 0,15 e 30 dias $(n=30)$

\begin{tabular}{|c|c|c|c|c|c|c|}
\hline \multirow[t]{2}{*}{ Dieta } & \multicolumn{2}{|c|}{ TO } & \multicolumn{2}{|c|}{ T15 } & \multicolumn{2}{|c|}{ T30 } \\
\hline & Média & $\pm D P$ & Média & $\pm \mathrm{DP}$ & Média & $\pm \mathrm{DP}$ \\
\hline Valor energético total (Kcal) & 2304 & $\pm 694,7$ & 2158,8 & $\pm 828,0$ & 2193,4 & $\pm 752,2 \mathrm{NS}^{*}$ \\
\hline Proteínas (g) & 85,1 & $\pm 33,6$ & 83,4 & $\pm 32,8$ & 89,6 & $\pm 30,2 \mathrm{NS}^{*}$ \\
\hline Proteínas (\%) & 14,8 & $\pm 3,5$ & 15,6 & $\pm 3,5$ & 16,7 & $\pm 4,0 \mathrm{NS}^{*}$ \\
\hline Carboidratos (g) & 299,6 & $\pm 85,0$ & 293,1 & $\pm 120,0$ & 280,9 & $\pm 119,3 \mathrm{NS}^{*}$ \\
\hline Carboidratos (\%) & 53,5 & $\pm 7,1$ & 54,4 & $\pm 7,1$ & 51,3 & $\pm 10,2 \mathrm{NS}^{*}$ \\
\hline Lipídeos (g) & 82,6 & $\pm 32,2$ & 74,1 & $\pm 34,1$ & 79,4 & $\pm 32,7 \mathrm{NS}^{*}$ \\
\hline Lipídeos (\%) & 31,3 & $\pm 29,9$ & 29,9 & $\pm 5,2$ & 32,5 & $\pm 8,3 \mathrm{NS}^{*}$ \\
\hline Ácidos graxos saturados (g) & 26,6 & $\pm 22,1$ & 22,1 & $\pm 11,2$ & 26,2 & $\pm 12,5 \mathrm{NS}^{*}$ \\
\hline Monoinsaturados $(\mathrm{g})$ & 29,4 & $\pm 12,8$ & 26,3 & $\pm 10,9$ & 29,4 & $\pm 12,2 \mathrm{NS}^{*}$ \\
\hline Poliinsaturados (g) & 17,3 & $\pm 8,4$ & 16,4 & $\pm 8,5$ & 17,9 & $\pm 9,7 \mathrm{NS}^{*}$ \\
\hline
\end{tabular}

$\mathrm{DP}=$ desvio padrão; NS = não significante $(p>0,05)$.

${ }^{*}$ Friedman. 
Tabela 2 - Composição de ácidos graxos da sardinha frita (\% do total de ácidos graxos)

\begin{tabular}{lclc}
\hline Ácidos graxos & $\%$ & Ácidos graxos & $\%$ \\
\hline $\begin{array}{l}\text { Saturados } \\
\text { Total }\end{array}$ & 21,47 & $\begin{array}{l}\text { Monoinsaturados } \\
\text { Total }\end{array}$ & 24,46 \\
Poliinsaturados & & Poliinsaturados & \\
Série $\omega 6$ & & Série $\omega 3$ & \\
$18: 2 \omega 6$ & 40,62 & $18: 3 \omega 3$ & 3,31 \\
$18: 3 \omega 6$ & 0,35 & $20: 5 \omega 3$ & 1,41 \\
$20: 4 \omega 6$ & 1,05 & $22: 5 \omega 3$ & 0,89 \\
& & $22: 6 \omega 3$ & 6,44 \\
Total $\omega 6$ & 42,02 & Total $\omega 3$ & 12,06 \\
Poliinsaturados & & & \\
Total $\omega 6+\omega 3$ & 54,07 & & \\
& & &
\end{tabular}

intervalo T0 e T15 e entre T0 e T30 dias, considerando o intervalo em dias.

Grupo 1 (consumo regular de peixe e último consumo próximo ao dia da coleta de leite - intervalo máximo de 3 dias): a nutriz consumiu o peixe de forma regular de duas a três vezes por semana, e o intervalo máximo entre coleta de leite e ingestão de sardinha correspondeu ao período de 3 dias;

Grupo 2 (consumo irregular de peixe e último consumo distante ao dia da coleta - intervalo mínimo de 4 dias): quando o consumo ocorreu de forma irregular, predominantemente na primeira semana, restando pequena quantidade na semana da coleta de leite, e o intervalo mínimo entre coleta de leite materno e ingestão de sardinha correspondeu ao período de 4 dias.

Tabela 3 - Composição do leite materno - gorduras totais ( $\mathrm{g} / \mathrm{dl}$ ), ácidos graxos (AG) (\% do total de ácidos graxos $)$ - T0, T15 e T30 $(\mathrm{n}=31)$

\begin{tabular}{|c|c|c|c|c|}
\hline Ácidos graxos & $\begin{array}{c}\text { To } \\
\text { Média } \pm \text { DP }\end{array}$ & $\begin{array}{c}\text { T15 } \\
\text { Média } \pm \text { DP }\end{array}$ & $\begin{array}{c}\text { T30 } \\
\text { Média } \pm \text { DP }\end{array}$ & \\
\hline \multicolumn{5}{|l|}{ Saturados } \\
\hline $10: 0$ & $1,72 \pm 1,00$ & $1,79 \pm 0,84$ & $1,85 \pm 0,61$ & NS * \\
\hline $12: 0$ & $7,00 \pm 2,59$ & $7,34 \pm 2,95$ & $6,71 \pm 2,31$ & NS * \\
\hline $14: 0$ & $7,56 \pm 3,08$ & $7,80 \pm 2,60$ & $7,33 \pm 3,34$ & NS * \\
\hline $16: 0$ & $20,31 \pm 1,78$ & $20,01 \pm 2,34$ & $19,09 \pm 2,13$ & NS * \\
\hline $18: 0$ & $5,90 \pm 1,15$ & $6,13 \pm 1,61$ & $6,46 \pm 1,58$ & NS * \\
\hline Total & $42,50 \pm 5,62$ & $43,07 \pm 6,18$ & $41,44 \pm 6,49$ & NS * \\
\hline \multicolumn{5}{|l|}{ Monoinsaturados } \\
\hline $16: 1$ & $3,09 \pm 0,88$ & $3,07 \pm 0,80$ & $4,06 \pm 1,52$ & NS * \\
\hline $18: 1$ & $30,52 \pm 3,99$ & $30,30 \pm 4,95$ & $30,26 \pm 5,13$ & NS * \\
\hline Total & $33,61 \pm 4,14$ & $33,37 \pm 5,43$ & $34,32 \pm 5,40$ & NS * \\
\hline \multicolumn{5}{|l|}{ Poliinsaturados série $\omega 6$} \\
\hline $18: 2 \omega 6$ & $20,72 \pm 3,78$ & $20,36 \pm 5,68$ & $20,95 \pm 5,10$ & NS * \\
\hline $18: 3 \omega 6$ & $0,26 \pm 0,08$ & $0,19 \pm 0,08$ & $0,21 \pm 0,06$ & NS * \\
\hline $20: 4 \omega 6$ & $0,56 \pm 0,14$ & $0,53 \pm 0,13$ & $0,51 \pm 0,10$ & NS * \\
\hline Total série $\omega 6$ & $21,55 \pm 3,77$ & $21,07 \pm 4,66$ & $21,66 \pm 5,14$ & NS * \\
\hline \multicolumn{5}{|l|}{ Poliinsaturados série $\omega 3$} \\
\hline $18: 3 \omega 3$ & $1,67 \pm 0,58$ & $1,74 \pm 0,53$ & $1,82 \pm 0,48$ & NS * \\
\hline $20: 5 \omega 3$ & $0,08 \pm 0,07$ & $0,07 \pm 0,05$ & $0,10 \pm 0,06$ & NS * \\
\hline $22: 5 \omega 3$ & $0,24 \pm 0,05$ & $0,23 \pm 0,08$ & $0,22 \pm 0,07$ & NS * \\
\hline $22: 6 \omega 3$ & $0,46 \pm 0,11$ & $0,52 \pm 0,28$ & $0,47 \pm 0,11$ & NS * \\
\hline Total série $\omega 3$ & $2,34 \pm 0,68$ & $2,49 \pm 0,82$ & $2,57 \pm 0,68$ & NS * \\
\hline Total $\omega 6+\omega 3$ & $23,89 \pm 4,03$ & $23,56 \pm 5,43$ & $24,23 \pm 5,65$ & NS * \\
\hline Gorduras totais ( $\mathrm{g} / \mathrm{dl}$ ) & $3,52 \pm 1,58$ & $3,58 \pm 1,55$ & $3,31 \pm 1,40$ & NS * \\
\hline \multicolumn{5}{|l|}{ Relação } \\
\hline Total $\omega 6$ :total $\omega 3$ & 7,50 & 7,00 & 7,10 & NS * \\
\hline $18: 2 \omega 6: 18: 3 \omega 3^{\dagger}$ & 14,00 & 12,00 & 11,80 & NS * \\
\hline $20: 4 \omega 6: 22: 6 \omega 3$ & 1,68 & 1,63 & 1,43 & NS * \\
\hline Correlação $\omega 6: \omega 3$ ₹ & & $r^{2}=0,58$ & $r^{2}=0,59$ & $\S$ \\
\hline
\end{tabular}

NS = não significante; * Friedman; † Relação $\omega 3 / \omega 6$ 5-15 $\left(\right.$ ESPGAN $\left.^{21}\right)$.; ${ }^{\ddagger}$ Correlação de Spearman; $\S^{p}<0,05$. 
Os AGP da série $\omega 6$ e $\omega 3$ foram relacionados quanto à regularidade do consumo de sardinha e o intervalo da ingestão e a coleta do leite materno nos tempos T15 (igual a $\Delta \% 1$ ) e T30 (igual a $\Delta \% 2$ ), sendo utilizado o teste de Mann-Whitney para essas análises (Tabela 4).

A análise da ingestão regular de sardinha no intervalo máximo de 3 dias, quando comparado à ingestão irregular no período mínimo de 4 dias (entre coleta de leite e ingestão de peixe), demonstrou que o primeiro grupo apresentou valores significantemente maiores de ácido docosapentaenóico (DPA) (22:5 13 - DPA) e DHA (22:6 $\omega 3$ - DHA) em T15 e DPA, DHA e soma de AGP da série $\omega 3$ $(A G P-\omega 3)$ em T30 $(p<0,05)$.

\section{Discussão}

A alimentação materna é de grande importância para o adequado desenvolvimento do feto e, posteriormente, para o lactente. Nos últimos anos, estudos foram e continuam sendo realizados com o objetivo de conhecer os fatores que podem afetar a qualidade do leite materno e suas possíveis conseqüências ${ }^{7,19}$.

Neste estudo, pôde-se observar a inter-relação da dieta com a composição do leite de nutrizes. Primeiramente, estudando-se a ingestão alimentar dessas mães, obtida pela média dos 3 dias de inquérito, observou-se que a distribuição de macronutrientes em relação ao valor energético total (VET) estava conforme o preconizado por Philippi et al. ${ }^{20}$ e não se observou variação da ingestão alimentar em diferentes tempos do estudo.

A análise dos AG do leite materno das mães estudadas revelou padrão distinto aos encontrados em outros estudos, refletindo os diferentes hábitos alimentares das populações.
No presente trabalho, no T0, os valores de DHA e a relação $\omega 6 / \omega 3$ não estão inadequados, mas limítrofes, apresentando-se próximos aos encontrados em populações ocidentais, em que há consumo de produtos industrializados e consumo reduzido de hortaliças e produtos marinhos ${ }^{9}$. As nutrizes apresentaram relação $\omega 6: \omega 3$ de 15:1 muito próxima ao limite superior ${ }^{21}$. No entanto, em T15 e T30, a relação $\omega 6: \omega 3$ esteve próxima a 12:1, compatível à dieta de países que consomem peixe regularmente ou do Mediterrâneo, que apresenta relação entre 10 e 12:1.

A porcentagem de AGP encontrada neste estudo, nos períodos T15 e T30, foram semelhantes às de trabalhos realizados no Panamá (linoléico $(19,87 \%), \alpha$-linolênico $(1,72 \%)$, eicosapentaenóico (EPA) $(0,09 \%)$ e total de $\omega 3$ $(2,53 \%)$ ) e no Congo (DPA $(0,24 \%)$, DHA $(0,55 \%)$ e total de AGP- $\omega 3$ 2,39\% ${ }^{7}$, e mais elevados do que os valores encontrados em populações da Europa e América do Norte 5,9 .

No Brasil, estudos em nosso meio avaliando os ácidos linoléico e linolênico no colostro e leite maduro observaram concentrações constantes independentemente das condições maternas. Apesar de diferentes níveis socioeconômicos, os óleos vegetais são largamente utilizados, seja o óleo de soja ou de milho $22-24$.

A análise desses AG no leite materno em diferentes estudos revela que, quando os níveis de linoléico (18:2 103 ) são mais altos, os níveis de $\alpha$-linolênico (18:3 133 ) também o são, o que parece refletir o nível de adaptação da síntese para manter o balanço entre esses ácidos $9,19,23$.

Existem evidências de competição entre os AG da série $\omega 6$ e $\omega 3$, uma vez que usam a mesma via de dessaturação para a formação de seus homólogos. Trabalhos relatam que, em situações nas quais ocorre inadequada dessaturação do ácido $\alpha$-linolênico, pode estar ocorrendo suplemento

Tabela 4 - Composição de ácidos graxos poliinsaturados do leite materno - T0, T15 e T30 (média do total de ácidos graxos \pm DP) Grupo 1 (ingestão de peixe regular e próximo à coleta de leite) e Grupo 2 (ingestão de peixe irregular e distante da coleta de leite) $(n=22)$

\begin{tabular}{lcccccc}
\hline $\begin{array}{l}\text { Ácidos graxos } \\
\text { poliinsaturados }\end{array}$ & Grupo 1 & Grupo 2 & Grupo 1 & Grupo 2 & Grupo 1 & Grupo 2 \\
\hline 18:2 $\omega 6$ & $21,48 \pm 3,66$ & $21,05 \pm 4,00$ & $22,59 \pm 4,00$ & $19,63 \pm 6,84$ & $24,11 \pm 5,16$ & $20,88 \pm 4,46$ \\
$18: 3 \omega 6$ & $0,22 \pm 0,12$ & $0,20 \pm 0,10$ & $0,19 \pm 0,06$ & $0,18 \pm 0,07$ & $0,18 \pm 0,09$ & $0,24 \pm 0,21$ \\
$20: 4 \omega 6$ & $0,55 \pm 0,16$ & $0,57 \pm 0,12$ & $0,56 \pm 0,17$ & $0,49 \pm 0,12$ & $0,46 \pm 0,10$ & $0,54 \pm 0,11$ \\
Total Série $\omega 6$ & $22,25 \pm 3,65$ & $21,81 \pm 3,94$ & $23,34 \pm 4,07$ & $20,30 \pm 6,91$ & $24,74 \pm 5,22$ & $21,65 \pm 4,45$ \\
$18: 3 \omega 3$ & $1,71 \pm 0,59$ & $1,77 \pm 0,70$ & $1,86 \pm 0,45$ & $1,85 \pm 0,64$ & $1,92 \pm 0,67$ & $1,92 \pm 0,40$ \\
$20: 5 \omega 3$ & $0,06 \pm 0,04$ & $0,09 \pm 0,11$ & $0,07 \pm 0,03$ & $0,07 \pm 0,05$ & $0,17 \pm 0,08$ & $0,06 \pm 0,02$ \\
$22: 5 \omega 3$ & $0,16 \pm 0,03$ & $0,25 \pm 0,10$ & $0,22 \pm 0,08^{*}$ & $0,20 \pm 0,03$ & $0,24 \pm 0,11^{*}$ & $0,23 \pm 0,07$ \\
$22: 6 \omega 3$ & $0,35 \pm 0,12$ & $0,44 \pm 0,25$ & $0,61 \pm 0,51^{*}$ & $0,45 \pm 0,20$ & $0,67 \pm 0,47^{*}$ & $0,41 \pm 0,21$ \\
Total Série $\omega 3$ & $2,22 \pm 0,57$ & $2,56 \pm 0,69$ & $2,74 \pm 0,70$ & $2,57 \pm 0,57$ & $3,00 \pm 0,89^{*}$ & $2,62 \pm 0,39$ \\
\hline
\end{tabular}

Teste de Mann-Whitney * $p<0,05$. 
insuficiente desse elemento ou as altas quantidades de ácido linoléico, comuns em fórmulas lácteas, podem estar inibindo ou limitando a capacidade de dessaturação e elongação do $\alpha$-ácido linolênico aos seus produtos ${ }^{25}$. Neste estudo, pôde-se observar correlação positiva entre os AG da série $\omega 6$ e $\omega 3$. Os maiores níveis de ácidos linoléico e $\alpha$-linolênico encontrados no estudo refletem o consumo constante e elevado de óleo de soja pelas mães antes e durante os períodos avaliados, inclusive para o preparo da sardinha, em que todas as nutrizes optaram por consumilas fritas. Esses AGP não apresentaram diferenças significativas nos três períodos avaliados.

A composição de AG de cadeia longa pode sofrer variações decorrentes desse processo, porém os valores obtidos na análise foram satisfatórios e dentro do esperado para esse tipo de peixe. Se a população estudada não tivesse o hábito de consumir óleo de soja regularmente para o preparo dos alimentos e para suas frituras, este poderia influenciar nos níveis de linoléico e $\alpha$-linolênico. Durante o processo de fritura, podem passar pequenas quantidades de AG de 20 e 22 carbonos para o óleo, porém essa conduta não influenciou os resultados encontrados após ingestão de peixes fritos. Provavelmente o hábito de alimentos fritos é uma prática regular nessa população.

Sabe-se que a mudança da qualidade da gordura da dieta materna pode influenciar o padrão de AG do leite produzido, dentro de 2 a 3 dias $^{26}$. Presa-Owens et al. ${ }^{5}$, estudando o padrão de $A G$ do leite de 40 nutrizes na Espanha, referiram que, apesar de o peixe apresentar maior

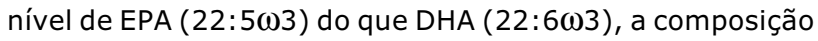
do leite de mulheres que consumiram grandes quantidades de peixe apresentou níveis maiores de DHA. Estudo de Henderson et al. ${ }^{11}$, utilizando óleo de peixe como suplemento para nutrizes, mostrou que o consumo de $1 \mathrm{~g}$ por dia de AGP de cadeia longa da série $\omega 3$ resultou em valores médios de $0,08 \%$ de EPA, $0,14 \%$ de DPA e $0,37 \%$ de DHA no leite secretado. Esses valores foram semelhantes aos encontrados no leite das nutrizes estudadas neste trabalho, em que se utilizou alimento de fácil aceitação e baixo custo, revelando que o consumo médio de três sardinhas (100$120 \mathrm{~g}$ ) por dia, duas a três vezes por semana, determinou maiores níveis daqueles $A G$, sem a necessidade de introduzir suplementos à base de óleos.

Estudos relatam que há correlação positiva entre os níveis de DHA e de AA no leite ${ }^{2,19}$. Há evidências de que existem mecanismos homeostáticos para regular a concentração sérica dos $A G$ de uma determinada série, como ocorre com os AG DHA, DPA e EPA ${ }^{19,25}$, sendo que, quando suplementados pela dieta, os dois primeiros são mais destinados aos depósitos, e o terceiro disponível em concentrações séricas ${ }^{3,27}$.

A análise do leite quanto à forma de consumo de peixe pelas mães revelou que a freqüência do consumo de sardinha e o intervalo entre o consumo e a coleta de leite foram os fatores determinantes de maiores níveis de AG da série 133 ; a regularidade do consumo (duas a três vezes por semana) e o intervalo até 3 dias entre a ingestão e a coleta mostraram valores significativamente maiores quanto à presença de DPA, DHA e total de $\omega 3$ no leite secretado. Este último apresentou níveis estatisticamente mais elevados no tempo T30. Esses achados podem ser justificados pelas considerações previamente feitas sobre a incorporação preferencial dos dois AG nos tecidos de depósitos.

Grande parte dos AGP secretados no leite materno são originados da síntese endógena e de estoques maternos, por meio de mecanismos regulatórios $3,4,19$. Assim, acredita-se que os níveis menores de EPA no leite são reflexos da regulação da entrada desse ácido graxo na glândula mamária, para que se mantenha a proporção adequada de $\omega 6 \omega 3$, já que os depósitos maternos estarão contribuindo com a série $\omega 3$ por meio de DHA e DPA 25,27 . Sabe-se, aliás, que a ingestão de EPA reflete-se principalmente nos seus níveis séricos e não nos depósitos $3,27,28$. Por outro lado, o EPA sérico tem participação especial no sistema imunológico, beneficiando os níveis de lipídeos séricos, reduzindo os riscos de agregação plaquetária, doenças ateroscleróticas e complicações trombóticas 25,28 .

Huang et al. ${ }^{29}$, em estudo experimental, observaram que a utilização de óleos de peixe na ração de ratas que estavam amamentando promoveu maior incorporação de DHA (22:6 $\omega 3)$ e DPA (22:5 $\omega 3)$ nos fosfolipídeos do coração da prole. A concentração de EPA (20:5 W3) nesse órgão foi menor, e o estudo acrescentou que os níveis desse ácido graxo são menos sensíveis às modificações da dieta. Outros estudos suplementando nutrizes com óleo de peixe encontraram níveis satisfatórios de AG da série $\omega 3$ no leite produzido, sugerindo que a presença do ácido $\alpha$-linolênico e EPA na dieta das mães pode ter contribuído para que o DHA estivesse significantemente elevado no leite ${ }^{8,10,11}$.

Harris et al. ${ }^{30}$, em seu estudo, concluíram que, para atingir os níveis desejados de DHA no leite materno, a ingestão de peixe deve ser muito elevada, tornando inviável seu consumo, pois, para atingir 0,5 a $1 \mathrm{~g}$ de DHA, seria necessário consumir de 350 a $750 \mathrm{~g}$ de peixes com $1 \%$ de gordura ou 75 a $150 \mathrm{~g}$ de peixes com $10 \%$ de gordura por dia. Neste estudo, no entanto, ocorreu aumento dos níveis habituais de DHA no leite materno utilizando-se consumo médio de $300 \mathrm{~g}$ de sardinha ( $5 \%$ de gordura) por semana, quando este consumo foi regular e próximo ao dia da coleta (intervalo inferior a 3 dias entre ingestão de peixe e coleta do leite). Assim, sugere-se que, para manter no leite materno os níveis da série $\omega 3$ constantemente elevados, deva-se consumir peixes de água salgada de duas a três vezes por semana.

\section{Agradecimentos}

Conselho Nacional de Desenvolvimento Científico e Tecnológico - CNPq, São Paulo, Brasil.

\section{Referências}

1. Martinez M. Tissue levels of polyunsaturated fatty acids during early human development. J Pediatr. 1992;120(4 Pt 2):S129-38.

2. Xiang M, Alfvén G, Blennow M, Trygg M, Zetterstrom R. Longchain polyunsaturated fatty acids in human milk and brain growth during early infancy. Acta Paediatr. 1999;89:142-7. 
3. Montgomery C, Speake KB, Cameron A, Sattar N, Weaver LT. Maternal docosahexaenoic acid supplementation and fetal accretion. Br J Nutr. 2003;90:135-45.

4. Koletzko B, Rodríguez-Palmero A, Demmelmair $H$, Fildler $N$, Jensen R, Sauerwald T. Physiological aspects of human milk lipids. Early Hum Dev. 2001;65(Suppl):S3-18.

5. Presa-Owens S, López-Sabater MC, Rivero-Urgell M. Fatty acid composition of human milk in Spain. J Pediatr Gastroenterol Nutr. 1996;22:180-5.

6. Jørgensen $M H$, Hernell O, Lund $P$, Hølmer G, Michaelsen KF. Visual acuity and erythrocyte docosahexaenoic acid status in breast-fed and formula-fed term infants during the first four months of life. Lipids. 1996;31:99-105.

7. Rocquelin G, Tapsoba S, Dop MC, Mbemba F, Traissac P, MartinPrével Y. Lipid content and essential fatty acid (EFA) composition of mature Congolese breast milk are influenced by mothers' nutritional status: impact on infants' EFA supply. Eur J Clin Nutr. 1998;52:162-71.

8. Lauritzen $L$, Jorgensen $M L$, Hansen $H S$, Michaelsen KF. Fluctuations in human milk long-chain PUFA levels in relation to dietary fish intake. Lipids. 2002;37:237-44.

9. Hartman L, Lago RC. Rapid preparation of fatty acid methyl esters from lipids. Lab Proc. 1973;22:475-7.

10. Jensen RG, Bitman J, Carlson SE, Couch SC, Hamosh M, Neuwburg DS. Human milk lipids. In: Jensen RG. The handbook of milk composition. San Diego: Academic Press; 1995. p. 495-537.

11. Henderson RA, Jensen RG, Lammi-Keefe CJ, Ferris AM, Dardick KR. Effect of fish oil on the fatty acid composition of human milk and maternal and infant erythrocytes. Lipids. 1992;27:863-9.

12. World Health Organization. Obesity: preventing and managing the global epidemic. Report of a WHO Consultation on Obesity. Geneva: WHO; 1997.

13. Thompson FE, Byers T. Dietary assessment resource manual. J Nutr. 1994;124(Suppl 11):S2245-317.

14. Anção MS, Cuppari L, Tudisco ES, Draibe AS, Sigulen D. Sistema de apoio à decisão em nutrição [programa de computador] versão 2.5. São Paulo: Centro de Informática em SaúdeUniversidade Federal de São Paulo (UNIFESP/EPM); 1995.

15. Marmet $C$. Extração manual do leite do seio: técnica de Marmet. In: Aleitamento materno: separata para profissionais. Folheto informativo 27. Los Angeles: La Leche League International; 1981.

16. Folch J, Lees M, Sloan-Stanley GH. A simple method for the isolation and purification of total lipids from animal tissue. J Biol Chem. 1957;226:497-509.

17. James AT, Martin AJ. Gas liquid chromatography: the separation and identification of the methyl esters of saturated and unsaturated acids from formic acid to n-octadecanoic acid. Biochem J. 1956;63:144-52.

18. Siegel S. Estatística no paramétrica. Cidade do México: Trillas; 1975.
19. Sauerwald TU, Demmelmair $H$, Koletzko B. Polyunsaturated fatty acid supply with human milk. Lipids. 2001;36:991-6.

20. Philippi ST, Latterza AR, Cruz AT, Ribeiro LC. Pirâmide alimentar adaptada: guia para escolha dos alimentos. Rev Nutr. $1999 ; 12: 65-80$.

21. ESPGAN Committee on Nutrition. Comment on the content and composition of lipids in infant formulas. Acta Paediatr Scand. 1991;80:887-96. (Committee Report)

22. Coelho MR, Nóbrega FJ. Estudo das gorduras totais, valor calórico total e proteínas totais no colostro de puérperas, segundo o nível sócio-econômico, o estado nutricional e a paridade. J Pediatr (Rio J). 1989;65:7-11.

23. Brasil AL, Vítolo MR, Ancona Lopez F, Nóbrega FJ. Fat and protein composition of mature milk in adolescents. J Adolesc Health Care. 1991;12:365-71.

24. Silva MP, Nóbrega FJ, Ancona Lopez F, Vítolo MR, Queiroz SS. Lipid composition (Total fats, caloric value and fatty acids) in the colostrum of adult nursing mothers of large for gestational age infants. In: Nóbrega FJ. Human milk composition. São Paulo: Revinter; 1996. p. 171-80.

25. Bell SJ, Bradley D, Forse RA, Bistrian BR. The new dietary fats in health and disease. J Am Diet Assoc. 1997;97:280-6.

26. Insull W, Hirsch J, James $T$, Ahrens EH. The fatty acids of human milk. II. Alterations produced by manipulation of caloric balance and exchange of dietary fats. J Clin Invest. 1959;38:443-50.

27. Marckmann P, Lassen A, Haraldsdóttir J, Sandström B. Biomarkers of habitual fish intake in adipose tissue. Am J Clin Nutr. 1995;62:956-9.

28. Vidgen HM, Agren JJ, Schwab U, Rissanen T, Hanninen O, Uusitupa MIJ. Incorporation of $n-3$ fatty acids into plasma lipid fractions, and erythrocyte membranes and platelets during dietary supplementation with fish, fish oil, and docosahexanoic acid - rich oil among healthy young men. Lipids. 1997;32:697705.

29. Huang YS, Wainwright PE, Redden PR, Mills DE, Bulman-Fleming $B$, Horrobin DF. Effect of maternal dietary fats with variable n$3 / n-6$ ratios on tissue fatty acid composition in suckling mice. Lipids. 1992;27:104-10.

30. Harris WS, Connor WE, Lindsey S. Will dietary $n-3$ fatty acids change the composition of human milk? Am J Clin Nutr. $1984 ; 40: 780-5$.

\section{Correspondência:}

Rose V. Patin

Rua Loefgreen, 1647, V. Clementino

CEP 04040-032 - São Paulo, SP

Tel./Fax: (11) 5573.1246.

E-mail: r.patin@uol.com.br, nutmet@terra.com.br 